\title{
Damage of a High-Energy Solid Propellant and Its Deflagration-to- Detonation Transition
}

\author{
Taihua Zhang*, Yilong L. Bai
}

State Key Laboratory for Nonlinear Mechanics (LNM), Institute of Mechanics, Chinese Academy of Sciences, Beijing 100080 (P.R. China)

\author{
Shiying Y. Wang, Peide D. Liu \\ Xi'an Modern Chemistry Research Institute, Xi'an 710065 (P.R. China)
}

\begin{abstract}
In order to assess the safety of high-energy solid propellants, the effects of damage on deflagration-to-detonation transition (DDT) in a nitrate ester plasticized polyether (NEPE) propellant, is investigated. A comparison of DDT in the original and impacted propellants was studied in steel tubes with synchronous optoelectronic triodes and strain gauges. The experimental results indicate that the microstructural damage in the propellant enhances its transition rate from deflagration to detonation and causes its increased sensitivity. It is suggested that the mechanical properties of the propellant should be improved to reduce its damage so that the probability of DDT might be reduced.
\end{abstract}

Keywords: Propellant, Damage, Deflagration-to-Detonation Transition (DDT)

\section{Introduction}

Experimental research on the mechanisms of deflagration-to-detonation transition (DDT) in porous energetic materials has been carried out for decades. Theoretical attempts have also been made to develop numerical models of DDT. For example, experimental work was performed at Naval Surface Weapons Center [1, 2], Los Alamos National Laboratory [3], Cavendish Laboratory [4], Franco-German Research Institute [5, 6], etc; theoretical work at University of Illinois at Urbana-Champaign [7, 8], etc. However, these studies mainly concerned the elucidation of several DDT stages and ignored the effect of damage in propellants.

In recent years, some previous results have shown that the deflagration-to-detonation transition (DDT) of high-energy solid propellants sometimes occurs with a ballistic malfunction, which can heavily damage propellants. Since the propellants were consumed, little is known about the nature of the damage (generated under the stress fields) which leads to DDT. For instance, James and Green have reported the following result observed in a $155 \mathrm{~mm}$ gun test [9]. DDT may occur after a primary shock of less than

* Corresponding author; e-mail: zhangth@lnm.imech.ac.cn
1.0 GPa has passed through the original cross-linked, double base (XLDB) propellant, leaving behind changed regions that may be reduced to a fractured rubble. The hot spot population and surface area are thereby increased. Secondary shocks passing through damaged propellants at levels as low as $70 \mathrm{MPa}$ have initiated XLDBs.

In this paper, we set up an experimental system to investigate the effects of damage on DDT of NEPE propellants. The aim is to develop a predictive way to describe the sensitivity of the NEPE propellant to damage.

\section{Sample Preparation}

\subsection{Ingredient}

The compositions of the propellants tested here are listed in Table 1. RDX and ammonium perchlorate (AP) were used as oxidizers. Al (aluminum powder) was used as fuel. Nitroglycerine (NG) and 1,2,4-butanetriol trinitrate (BTTN) were used as plasticizers. Polythyelne glycol (PEG) was used as the binder. N-100 (hexane 1,6-diisocyanate homopolymer) was used as crosslinking agent.

\subsection{Damage Production}

In order to reduce the vulnerability of rocket systems to low velocity projectile/fragment impact or drop during transport, a fundamental understanding of the intermediate strain-rate behavior of the NEPE propellants is important. A hammer of $400 \mathrm{~kg}$ mass in a large-scale drop weight test was dropped under gravity from a height of $0.25 \mathrm{~m}$ to impact the sample. The processed propellants were machined into cylindrical samples of $40 \mathrm{~mm}$ diameter and $10 \mathrm{~mm}$ thickness for these impact tests. The apparatus and the typical loadtime curve are shown in Figure 1(a)and 1(b). In Figure 1(b), the peak pressure is $\mathrm{p}_{\mathrm{m}}=145 \mathrm{MPa}$ and the average axial strain-rate $\dot{\varepsilon}=v / L=\sqrt{2 g H} / L \sim 10^{2} s^{-1}$. From the observed stress-time curve (Figure 1(b)), various deformation proc- 
Table 1. Propellant compositions.

\begin{tabular}{|c|c|c|c|c|c|c|c|}
\hline \multirow{3}{*}{$\begin{array}{l}\text { Ingredients } \\
\text { Weight }(\%) \\
\text { Particle size }(\mu \mathrm{m})\end{array}$} & \multicolumn{4}{|c|}{ Solid (75\%) } & \multicolumn{3}{|c|}{ Liquid (25\%) } \\
\hline & RDX & AP & $\mathrm{Al}$ & Catalyst & NG/BTTN & PEG & N-100 \\
\hline & 40 & 16 & 18 & 1 & 19 & 5 & 1 \\
\hline
\end{tabular}

(a)
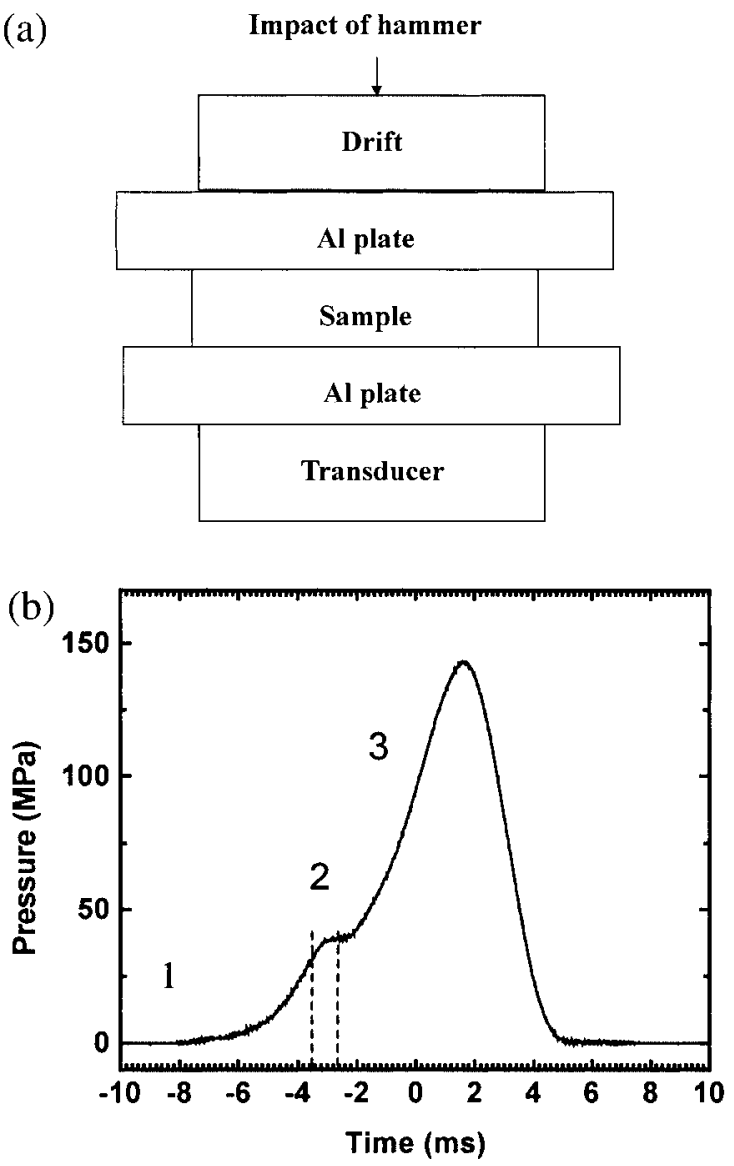

Figure 1. (a) Schematic diagram of impact test, (b) load-time curve.

esses may occur. In Stage 1, extensive viscoelastic/plastic deformation occurs. In Stage 2, the sample was extensively crushed out and the pressure remained at ca. $39 \mathrm{MPa}$. In Stage 3, the pressure sharply increased. During impact, the sample underwent deformation so extensively that most of the sample was squeezed out from the two Al plates and only a thin layer was left. After impact, the sample almost fully recovered, and cracks were not visible on the sample surface. This phenomenon implies that the propellant exhibits some characteristics of elastomeric polymers undergoing quasi-rubber-like deformation.

\subsection{Damage Characterization}

The damage in the samples subjected to the drop weight loading was evaluated by means of scanning electron microscopy (SEM) and density measurements.

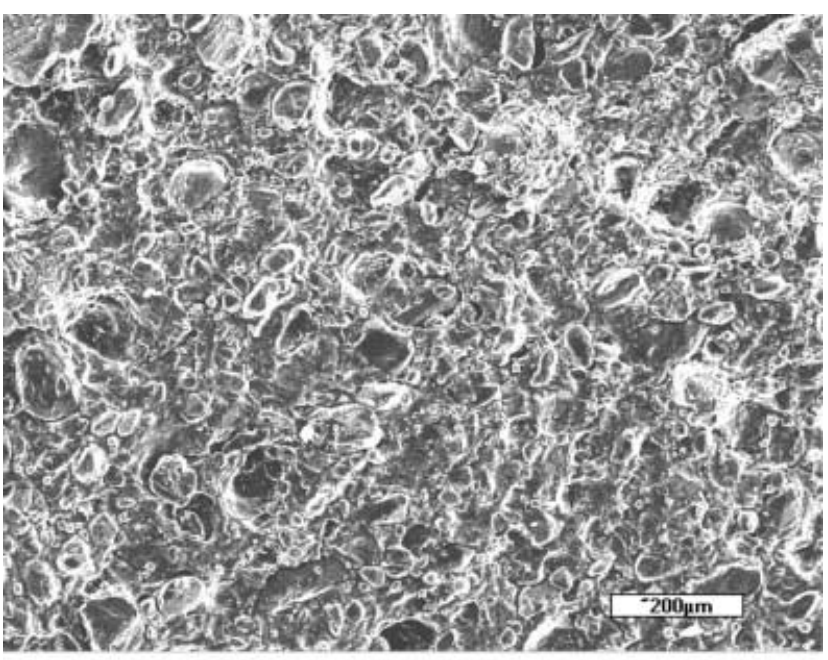

(a) $100 x$

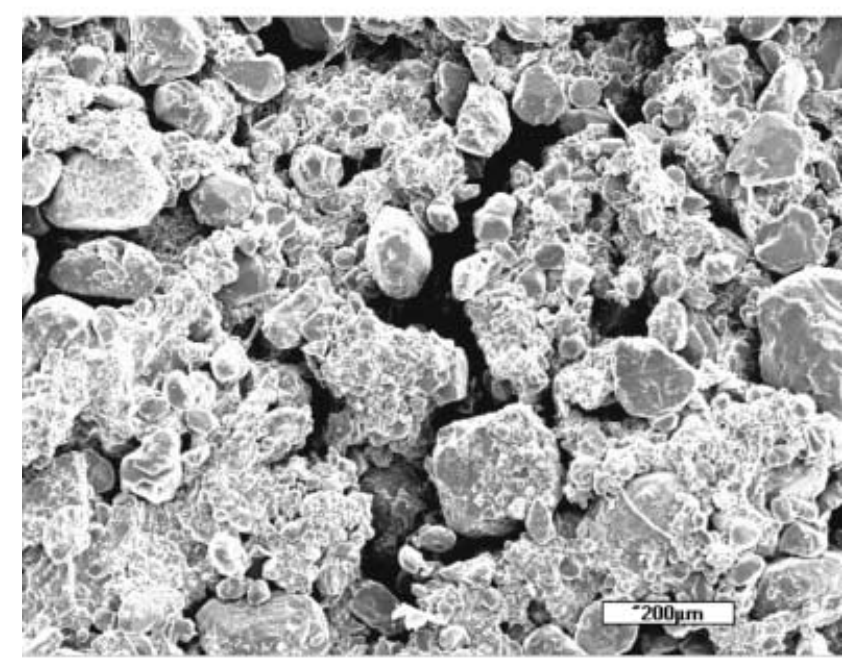

(b) $100 \times$

Figure 2. (a) The origin sample, (b) the impacted sample.

The samples did not exhibit visible cracks. So, SEM was used to examine the sections of the original and impacted samples in order to identify damage modes under the impact condition. Firstly, we should keep the following facts in mind. The NEPE propellant is an energetic composition containing various particle sizes of RDX, AP and $\mathrm{Al}$ powders. Its matrix is made up from a great deal of energetic plasticizer nitrate ester $(\mathrm{NG}+\mathrm{BTTN})$ and polyurethane binder $(\mathrm{PEG}+\mathrm{N}-100)$. The surface of a RDX crystal is inert 


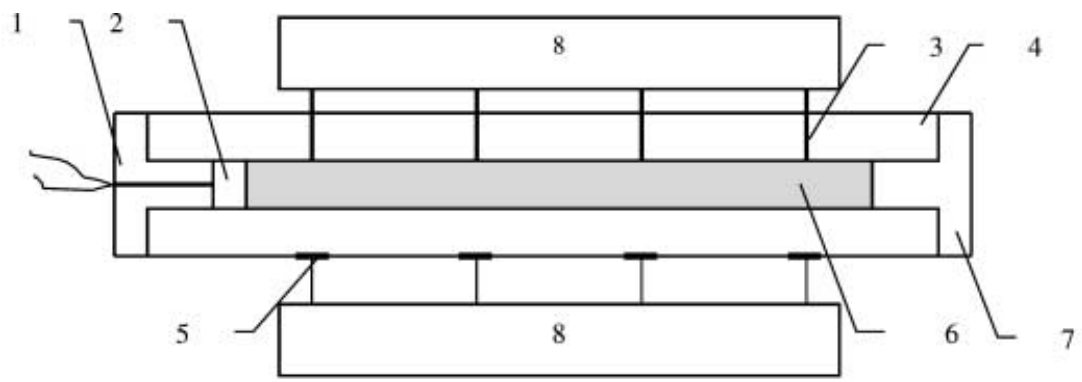

\section{Igniter bolt 2. Igniter 3. Optoelectronic triode 4. Steel tube 5 . Strain gauge \\ 6. Charge bed 7. End closure 8. Oscilloscope}

Figure 3. Scheme of the arrangement.

so that RDX crystals in the propellant were weakly bonded to the matrix.

The SEM micrograph from a microtomed cross section of the original sample is shown in Figure 2(a). The polyurethane binder adhered to the crystal surfaces of the filled RDX particles poorly. For instance, there appeared seams in the range of $10^{0} \mu \mathrm{m}-10^{1} \mu \mathrm{m}$ between RDX particles and the matrix. Thus, the bigger RDX particles easily went apart at the seams. In order to improve the adhesive properties of the matrix and the filled particles, a suitable binding agent should be used or the filled particles should be coated to restrain dewetting.

Compared to the original samples, the impacted samples show changes (Figure 2(b)) in two ways:

(1) The matrix was torn. Between the bigger particles and the voids in the matrix, a lot of microcracks were formed and propagated.

(2) Bigger particles debonded. The bigger particles were separated from the matrix, but the particles themselves were not disrupted. At the same time, smaller particles were still coated with matrix.

Due to damage, the volume and the density of the sample change. The damage variable is expressed as in Ref. 3:

$D_{\rho}=\left(1-\rho_{1} / \rho_{0}\right)^{2 / 3}$

Damage is defined here as a scalar quantity. $D_{\rho}$ denotes the extent of damage in the impacted sample, $0 \leq D_{\rho} \leq 1$. $D_{\rho}=0$ corresponds to the undamaged condition, whereas $D_{\rho}=1$ corresponds to complete material failure. $\rho_{0}$ and $\rho_{1}$ are the densities of the original and the impacted samples, respectively.

Based on Archimedes' principle, the mass of the sample was weighed with a scale (precision $0.0001 \mathrm{~g}$ ) in air and in liquid (paraffine oil). The densities of the original and impacted samples were $1.793 \mathrm{~g} / \mathrm{cm}^{3}$ and $1.777 \mathrm{~g} / \mathrm{cm}^{3}$, respectively. So, the damage variable $D_{\rho}$ is 0.043 .

\section{DDT Arrangement}

The DDTexperimental arrangement is shown in Figure 3. The arrangement is made up of a thick-walled steel tube (20 $\mathrm{mm}$ inner diameter, $64 \mathrm{~mm}$ outer diameter, $500 \mathrm{~mm}$ length), closed at both ends with screw caps. In the tube, there are a $50 \mathrm{~mm}$ igniter and a propellant charge bed $420 \mathrm{~mm}$ long.

In order to understand the effects of damage of the propellant on DDT, two types of granular propellants were prepared as follows. Both impacted and original samples were cut with a microtome into regular $5 \times 5 \times 5 \mathrm{~mm}^{3}$ cubic grains. Finally, $150 \mathrm{~g}$ grains of the original or impacted propellants were put into each tube with a density of $1.076 \mathrm{~g} / \mathrm{cm}^{3}$ (60\% TMD), respectively.

The igniter consists of $1.5 \mathrm{~g} \mathrm{NC}$ (nitrocellulose) powders and an electric fuse. An electric fuse was heated by $30 \mathrm{VDC}$ voltage, then the charge bed was ignited.

Two kinds of gauges were distributed along the tube as shown in Figure 3. Four optoelectronic triodes (model 3DU2D, response time $3.0 \mu \mathrm{s}$ ) detected the passage of the flame front, and other four strain gauges (BH350-4AA) detected the profiles of the compacted/shocked waves. The signals were recorded with two TDS544A four-channel digital oscilloscopes (Tektronix Corp., sample rate $1 \mathrm{GS} / \mathrm{s}$ ). Additionally, we also used 8 optoelectronic triodes, to survey the passage of the flame front in DDT.

\section{Results and Analyses}

In our paper, we list the results for four tests, Tests No. 1 and No. 3 are for the original propellant and Tests No. 4 and No. 6 for the impacted one. The parameters of tests and the characteristic average velocity of the waves are listed in Tables 1-4 for Tests No. 1, 3, 6 and 4, respectively. Typical outputs of the optoelectronic triodes and strain gauges are given in Figure 4 and Figure 5 for Tests No. 1 and No. 3. The two oscilloscopes were simultaneously triggered by the igniting voltage of the electric fuse. Hence, the initial time 
Table 2. Results of Test No. 1.

\begin{tabular}{|c|c|c|c|c|c|c|c|c|c|c|c|c|}
\hline \multicolumn{7}{|c|}{ Optoelectronic Triodes } & \multicolumn{6}{|c|}{ Strain Gauges } \\
\hline Distance $(\mathrm{cm})$ & 9.5 & & 20.0 & & 30.5 & 41.0 & 6.0 & 16.5 & & 27.0 & & 37.5 \\
\hline Time $(\mathrm{ms})$ & 10.92 & & 11.48 & & 11.60 & 11.68 & 11.88 & 11.84 & & 11.76 & & 11.68 \\
\hline Distance interval $(\mathrm{cm})$ & & 10.5 & & 10.5 & & & & & 10.5 & & 10.5 & \\
\hline Time interval (ms) & & 0.56 & & 0.12 & & & & & -0.08 & & -0.08 & \\
\hline Average velocity $(\mathrm{km} / \mathrm{s})$ & & 0.19 & & 0.88 & & & & & -1.31 & & -1.31 & \\
\hline
\end{tabular}

Table 3. Results from optoelectronic triodes of Test No. 3.

\begin{tabular}{|c|c|c|c|c|c|c|c|c|c|c|c|c|c|c|c|}
\hline Distance $(\mathrm{cm})$ & 2.5 & & 9.5 & & 16.5 & & 23.5 & & 30.5 & & 34.0 & & 37.5 & & 41.0 \\
\hline Time (ms) & 12.468 & & 13.216 & & 13.564 & & 13.694 & & 13.802 & & 13.844 & & 13.876 & & 13.914 \\
\hline Distance interval $(\mathrm{cm})$ & & 7.0 & & 7.0 & & 7.0 & & 7.0 & & 3.5 & & 3.5 & & 3.5 & \\
\hline Time interval (ms) & & 0.748 & & 0.348 & & 0.130 & & 0.108 & & 0.042 & & 0.032 & & 0.038 & \\
\hline Average velocity $(\mathrm{km} / \mathrm{s})$ & & 0.09 & & 0.20 & & 0.54 & & 0.65 & & 0.83 & & 1.09 & & 0.92 & \\
\hline
\end{tabular}

(a)

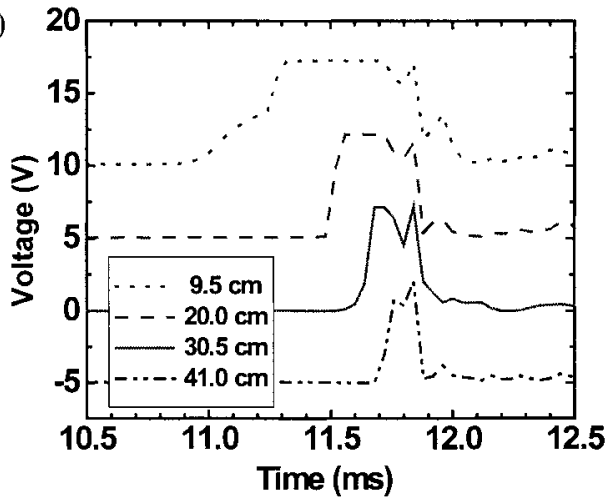

(b)

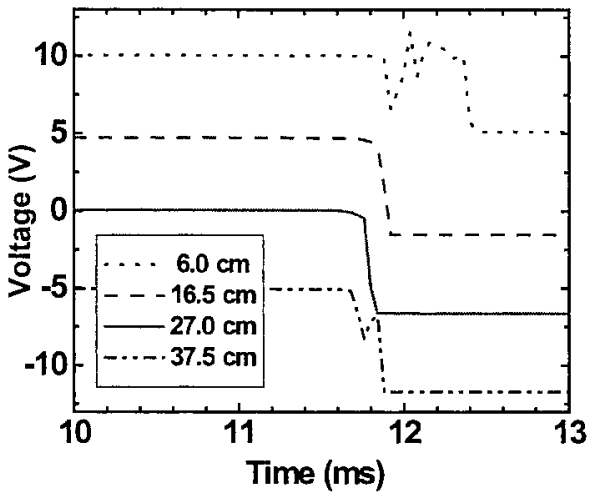

Figure 4. (a) Otpoelectronic triode curves, (b) strain gauge curves of Test No. 1.

$\mathrm{t}=0$ is the moment when the fuse ignited. The legends in insets indicate the locations of gauges along the charge bed. The starting points are all the interfaces between the igniter and the charge. The base voltages of all signals are zero. For clarity, some were shifted upward. Figure 6 shows the comparison of distance-time and velocity-time plots of the waves for original (Test No. 3) and impacted (Test No. 4) propellants. Figure 7(a) and (b) are the photos of the tested steel tubes.

Propellants, Explosives, Pyrotechnics 28 (2003), No. 1
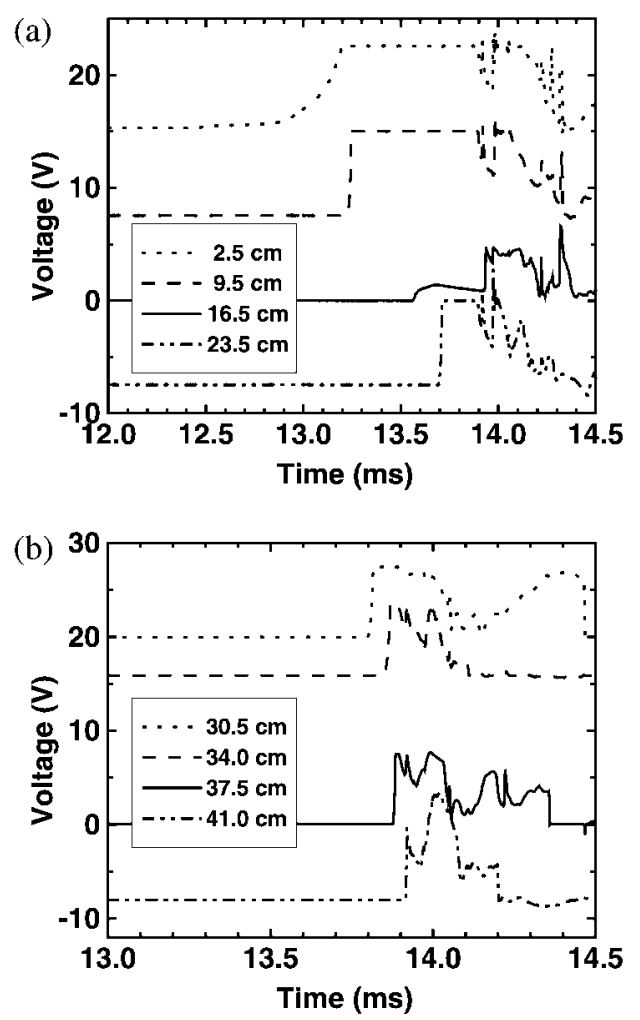

Figure 5. Optoelectronic triode curves of Test No. 3.

\subsection{Original Propellant}

The experimental results are listed in Table 2 and Table 3. The typical signal curves are presented in Figure 4 and Figure 5. If one turns to Figure 6, DDT is more clearly seen. The acceleration of flame fronts, as shown in Figure 6(b), obviously indicates a DDT and has been explained by many authors (see e.g. Ref. 1).

Let us have a close look at DDT. In the pre-ignition stage, $1.5 \mathrm{~g} \mathrm{NC}$ was ignited to initiate a very slow burning and to 

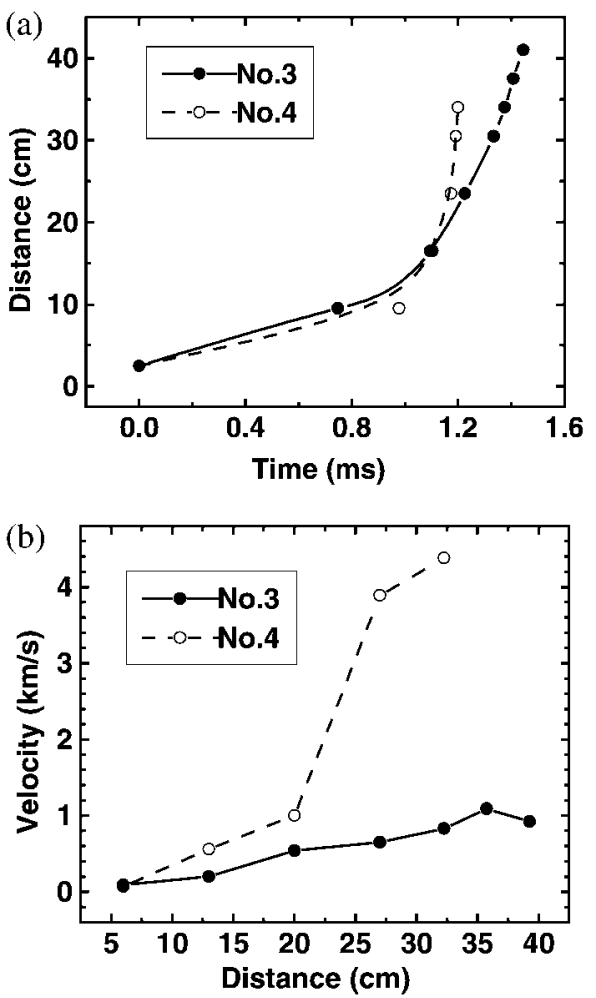

Figure 6. Comparison of the original propellant (Test No. 3) and the impacted propellant (Test No. 4).

(a) distance-time curves (b) velocity-distance curves

generate high-temperature product gases. The product gases, confined in the thick-walled steel tube, compressed the porous charge bed and ignited the charge bed. The ignition spreads slowly (Figure 5). Moreover, the first signal $(2.5 \mathrm{~cm})$ rose slowly, indicating that convective burning had started. This was called the ignition/conductive burning stage. Generally, these two stages took the greater part of time in DDT. The ignition spreads slowly. In the convective burning stage, due to the porosity of the charge bed, hightemperature gas may penetrate into the unreacted charge bed. Then the unreacted bed was heated and ignited. In the third stage (compressive stage), the burning rate increased fast from about $0.09 \mathrm{~km} / \mathrm{s}$ between $2.5 \mathrm{~cm}$ and $9.5 \mathrm{~cm}$ to $0.2 \mathrm{~km} / \mathrm{s}$ between $9.5 \mathrm{~cm}$ to $16.5 \mathrm{~cm}$ (see Table 3 ). In Figure $5(\mathrm{a})$, the third signal $(16.5 \mathrm{~cm})$ rose slightly at about $13.6 \mathrm{~ms}$ and changed fast at $13.9 \mathrm{~ms}$. At this stage a plug had formed in the compressed porous charge bed. Its width was approximately $6 \mathrm{~cm}$. From then on, the compressive burning rates increased continuously. Finally, within $34.0 \mathrm{~cm}$ and $37.5 \mathrm{~cm}$, compressive waves built up a detonation with a speed of $1.09 \mathrm{~km} / \mathrm{s}$.

As shown in Figure 4 and Table 2, the response time of earlier signals of strain gauges fell behind those of optoelectronic triodes. Moreover, the data of strain gauges indicate that the wave accelerated backward. The fragments of the steel tube (see Figure 7(a)) showed that detonation happened in Test No. 1.

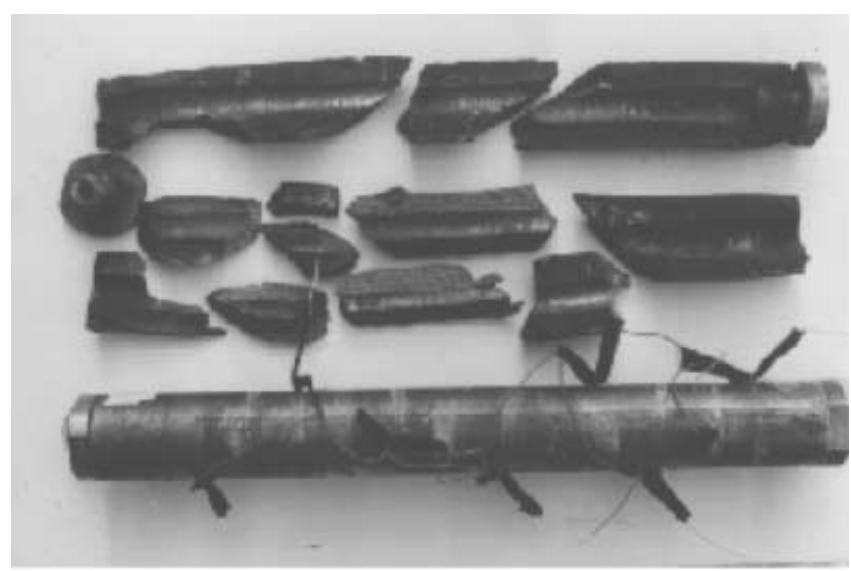

(a)

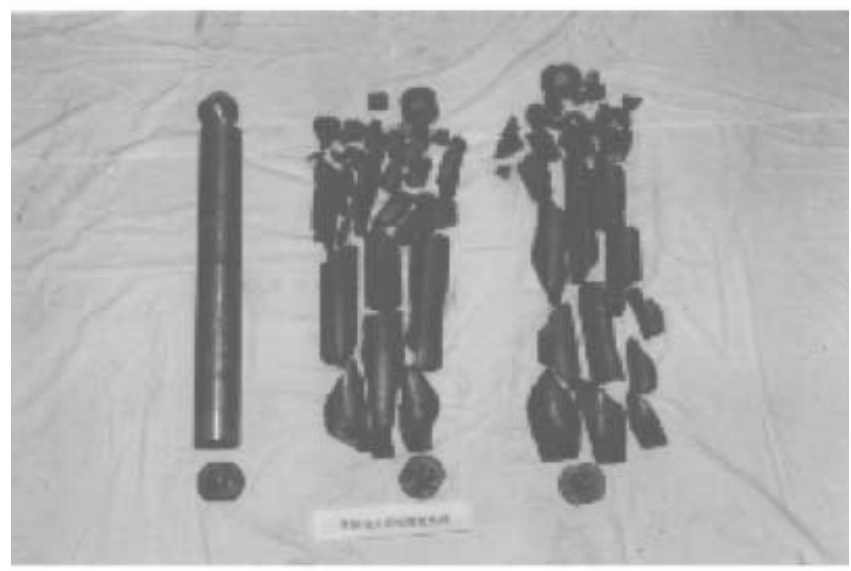

(b)

Figure 7. (a) Test No. 1 tube broken and Test No. 3 original tube, (b) Test No. 4 and Test No. 6 tubes broken.

\subsection{Impacted Propellant}

Experimental data are listed in Table 4 and Table 5. The DDT mechanism of the impacted propellant is basically the same as the original propellant. However, there are two salient differences:

(1) In Figure 6(a), to facilitate comparison, the initial time $\mathrm{t}=0$ in both tests, No. 3 and No. 4, are shifted to the arrival time of the flame front at location distance $2.5 \mathrm{~cm}$. From Figure 6(a) and (b), the burning rate of the impacted propellant is faster than that of the original propellant. Moreover, a steep increase of the burning rate showed that a stronger wave had formed near $23.5 \mathrm{~cm}$. Actually, detonation took place $(\mathrm{v}=6.56 \mathrm{~km} /$ s), see Test No. 6 in Table 4.

(2) As shown from Figure 7(a) and Figure 7(b), the steel tubes fragments from Test No. 4 and No. 6 are smaller than those formed by the detonation of the original propellant.

The two differences indicate that damaging the propellant would increase the burning rate, and so maybe cause a hazard. 
Table 4. Results of Test No. 6.

\begin{tabular}{|c|c|c|c|c|c|c|c|c|c|c|}
\hline \multirow[b]{2}{*}{ Distance $(\mathrm{cm})$} & \multicolumn{6}{|c|}{ Optoelectronic Triodes } & \multicolumn{4}{|c|}{ Strain Gauges } \\
\hline & 2.5 & 6.0 & 13.0 & 16.5 & 23.5 & 27.0 & 2.5 & 13.0 & 23.5 & 34.5 \\
\hline Time $(\mathrm{ms})$ & 9.844 & 10.502 & 11.350 & 11.466 & 11.500 & 11.510 & 11.608 & 11.496 & 11.446 & 11.462 \\
\hline Distance interval $(\mathrm{cm})$ & 3.5 & 7.0 & 3.5 & 7.0 & 3 & & 10.5 & 10.5 & & \\
\hline Time interval (ms) & 0.658 & 0.848 & 0.116 & 0.034 & & & -0.112 & -0.050 & & \\
\hline Average velocity $(\mathrm{km} / \mathrm{s})$ & 0.05 & 0.08 & 0.30 & 2.06 & & & -0.94 & -2.10 & & \\
\hline
\end{tabular}

Table 5. Results from optoelectronic triodes of Test No. 4.

\begin{tabular}{|c|c|c|c|c|c|c|c|c|c|c|c|c|c|c|c|}
\hline Distance $(\mathrm{cm})$ & 2.5 & & 9.5 & & 16.5 & & 23.5 & & 30.5 & & 34.0 & & 37.5 & & 41.0 \\
\hline Time (ms) & 10.158 & & 11.136 & & 11.262 & & 11.332 & & 11.350 & & 11.358 & & - & & - \\
\hline Distance interval $(\mathrm{cm})$ & & 7.0 & & 7.0 & & 7.0 & & 7.0 & & 3.5 & & 3.5 & & 3.5 & \\
\hline Time interval (ms) & & 0.978 & & 0.126 & & 0.070 & & 0.018 & & 0.008 & & - & & - & \\
\hline Average velocity $(\mathrm{km} / \mathrm{s})$ & & 0.07 & & 0.56 & & 1.00 & & 3.89 & & 4.38 & & - & & - & \\
\hline
\end{tabular}

\section{Discussion and Conclusions}

The investigated propellant can undergo extensive elastic deformation under mechanical loading. It is a very viscoelastic material. In comparison with the microstructure of the original sample, there are two kinds of changes in the impacted sample: matrix tearing and the bigger RDX particles debonded. These changes greatly increase the surface area. Moreover, measuring the changes of density can be used to quantify the damage.

The experimental results, for example Tests No. 3 and No. 4 , clearly show the influence of damage on DDT. This should be attributed to the higher surface to volume ratio of the damaged propellant. In order to reduce the probability of DDT, the mechanical properties of a propellant should be improved to redcue its damage on mechanical loading.

Optoelectronic triodes are an effective and reliable way of making these measurements. Under certain circumstances (e.g. the above tests), ionization probes did not respond in the initial burning stages and optical fiber assemblies were too complicated. In our tests optoelectronic triodes provide relatively reliable, inexpensive and simple recordings of flame propagation.

Overall, the above results indicate that damage induced by impact could result in an increase in transition rate from deflagration to detonation.

In this paper, we investigated the effects of damage on DDT of a NEPE propellant. In the future, the aim is to develop a predictive model to describe the sensitivity of NEPE propellants depending on damage.

\section{References}

[1] R. R. Bernecker, H. W. Sandusky, and A. R. Clairmont, Deflagration-to-Detonation Transition (DDT) Studies of a
Double-Base Propellant, 8th Symposium (Int.) on Detonation, Albuquerque, NM, July 15-19, 1985, p. 658.

[2] H. W. Sandusky, and R. R. Bernecker, Compressive Reaction in Porous Beds of Energetic Materials, 8th Symposium (Int.) on Detonation, Albuquerque, NM, July $15-19, \mathbf{1 9 8 5}$, p. 881.

[3] J. M. McAfee, B. W. Asay, A. W. Campbell, and J. B. Ramsay, Deflagration to Detonation in Granular HMX, 9th Symposium (Int.) on Detonation, Portland, OR, August 28 - September 1, 1989, p. 265.

[4] P. E. Luebcke, P. M. Dickson, and J. E. Field, Deflagration to Detonation in Granular HMX, 9th Symposium (Int.) on Detonation, Portland OR, 27 August - 1 September 1989, p. 144.

[5] M. Samirant, DDT in RDX and Ball Powder: Behavior of the Porous Bed, 8th Symposium (Int.) on Detonation, Albuquerque, New Mexico, 15-19 July 1985, p. 972.

[6] M. Samirant, DDT-Determination of the Successive Phases of Phenomena, 9th Symposium (Int.) on Detonation, Portland, OR, August 28 - September 1, 1989, p. 259.

[7] P. B. Butler, M. F. Lembeck, and H. Krier, Modeling of Shock Development and Transition to Detonation Initiated by Burning in Porous Propellant Beds, Combust. Flame 1982, 46,75 .

[8] P. B. Butler, and H. Krier, Analysis of Deflagration to Detonation Transition in High-Energy Solid Propellants, Combust. Flame 1986, 63, 31.

[9] E. James, Propellants and Explosives in Ballistic Missiles, Report DE93-018914, 1993, Lawrence Livermore National Laboratory, Livermore, CA, USA.

\section{Acknowledgements}

This research was supported by the National Natural Science Foundation of China (10242001, 10172086), Chinese Academy of Sciences (KJCX2-SW-L2).

(Received January 30, 2002; Ms 2002/004) 